\title{
Lycopene's effects on cancer cell functions within monolayer and spheroid cultures
}

Nina Pauline Holzapfel ${ }^{1 *}$, Boris Michael Holzapfel ${ }^{1}$, Christina Theodoropoulos ${ }^{1}$, Elke Kaemmerer ${ }^{1}$, Tamara Rausch ${ }^{2}$, Jesper Feldthusen ${ }^{2}$, Simon Champ ${ }^{2}$, Judith Ann Clements ${ }^{1,3}$, Dietmar Werner Hutmacher ${ }^{1,4,5, *}$ and Daniela Loessner ${ }^{1}$

1 Institute of Health and Biomedical Innovation, Queensland University of Technology, 60 Musk Avenue, Kelvin Grove, QLD 4059, Brisbane, Australia

2 Human Nutrition, BASF SE, G-ENH/MB, 68623 Lampertheim, Germany

3 Australian Prostate Cancer Research Centre, Translational Research Institute, 37 Kent Street, Woolloongabba, QLD 4102, Brisbane, Australia

4 The George W. Woodruff School of Mechanical Engineering, Georgia Institute of Technology, 801 Ferst Drive Northwest, Atlanta, GA 30332, USA

5 Institute of Advanced Study, Technical University of Munich, Lichtenbergstr. 2a, 85748 Garching, Munich, Germany

* Authors to whom correspondence should be addressed:

Address: Institute of Health and Biomedical Innovation, Queensland University of Technology, 60 Musk Avenue, Kelvin Grove, QLD 4059, Brisbane, Australia

Phone: +61-7-3138-6288; +61-7-3138-6077

Fax: $+61-7-3138-6040$

Email: ninapauline.holzapfel@qut.edu.au; dietmar.hutmacher@qut.edu.au

Running title: Lycopene's effects on cancer cell functions

Keywords: lycopene, breast cancer, prostate cancer, ovarian cancer, spheroid cultures 


\section{Abstract}

Lycopene, a compound that blocks the action of free radicals and oxygen molecules, is found in tomatoes and tomato-based products and linked to a reduced incidence of cancer. Increasing willingness of patients to maintain a healthy lifestyle by supplemental intake of nutrients and acceptance of alternative therapeutics has boosted research into nutraceuticals. Lycopene's potential to prevent or treat cancer has been investigated, but outcomes are inconsistent and its mode of action is still unknown. Further studies are needed to understand the role of lycopene in cancer prevention and treatment. The impact of lycopene on viability, proliferation, migration, and invasion of five different cancer cell lines was determined using monolayer and spheroid cultures. Cell viability was significantly reduced upon lycopene treatment at physiologically attainable concentrations. Cell proliferation, migration, and invasion did not change upon lycopene treatment. Ovarian cancer spheroids initially showed a decreased proliferation and after 14 days increased cell viability upon lycopene treatment, confirming the potential of lycopene to reduce cancer cell growth in short-term cultures and indicate also enhanced cell viability over prolonged exposure. This study cannot substantiate that lycopene inhibits cell functions associated with tumor growth; even in a 3D cancer model that mimics the natural tumor microenvironment. 


\section{Introduction}

A balanced diet, following the rule of consuming five portions of fruit and vegetables per day, has been associated with a reduced incidence of diseases, such as cancer and coronary heart disease $[1,2]$. While a high intake of animal fat, milk, and red meat seems to increase cancer risk, a diet rich in antioxidants, present in fruits and vegetables, is discussed to have chemo-preventive effects against breast, prostate, and ovarian cancer [2, 3]. This has also been shown for the intake of vitamins like vitamin E, beta-carotene or lycopene [4]. Antioxidants are known to reduce oxidative stress and DNA damage by inactivating free radicals. Furthermore, they are capable to selectively induce apoptosis in malignant cells, while, at the same time, sparing healthy cells [5].

Containing a big variety of biologically active ingredients, most of these fruits and vegetables have a long history in the use as traditional medicines [6]. Steadily increasing sales figures of dietary or food supplements have resulted in an increased interest of the scientific community in the chemo-preventive potential of specific nutrients [3]. In 1989, Stephen DeFelice created the term "nutraceutical" by combining "nutrition" and "pharmaceutical" [7]. According to his definition, a nutraceutical is "a food, or part of a food, that provides medical or health benefits, including the prevention and/or treatment of a disease" [8]. Unlike dietary supplements, a nutraceutical has the function, besides supplementing the diet, to prevent or treat diseases [7]. Within this context, the interest in lycopene-rich diets and supplements for the prevention or therapy of different tumor entities, such as breast, prostate, and ovarian cancer, has increased during the last years.

Lycopene, naturally occurring in many fruits and vegetables like tomatoes, papaya, watermelon or pink grapefruit, belongs to the group of carotenoids. It is highly potent towards oxygen in terms of overall capacity in inactivating free radicals within an organism. Its antioxidant properties are suggested to play a fundamental role in the prevention of cancer and other chronic diseases [9]. Besides vitamins $\mathrm{D}$ and $\mathrm{E}$ as well as selenium and green tea 
polyphenols, lycopene is suggested to be one of the most promising natural anti-cancer compounds [3]. Prevention of oxidative DNA damage in tumor cells, decrease of tumor cell proliferation, reduction of migratory and invasive behavior as well as induction of apoptosis are only a few of the discussed potential mechanisms of lycopene [9]. However, due to inconsistencies in experimental, preclinical and clinical study outcomes and an unknown mode of action, it is still questionable if there is a clear evidence to recommend the supplemental intake of lycopene to patients in addition to a well-balanced diet. The American Institute for Cancer Research (AICR) classifies lycopene as a compound that shows limited evidence for cancer prevention, and therefore, the AICR is not conclusive in its recommendation regarding supplemental lycopene intake. However, the AICR clearly states that lycopene-containing food remains important to maintain a healthy, cancer-protective diet [10].

The aim of this study was to investigate the anti-proliferative, anti-migratory and anti-invasive properties of lycopene on classical monolayer cultures, using different breast, prostate, and ovarian cancer cell lines; belonging to the group of hormone-dependent cancer entities. As a proof of concept, the impact of lycopene on viability and proliferation of two different ovarian cancer cell lines grown in spheroid cultures was examined, as they reflect a physiologically relevant model to study the behavior of cancer cells within their natural tumor microenvironment. To our knowledge, this is the first study to test the effects of lycopene on ovarian cancer cells using a three-dimensional (3D) cell culture approach. 


\section{Methods}

Cell culture. MDA-MB-231 breast cancer, PC-3 and LNCaP prostate cancer, and SKOV-3 ovarian cancer cells were obtained from the American Type Culture Collection (ATCC; Manassas, VA, USA). MDA-MB-231 cells were derived from a pleural effusion of a metastatic adenocarcinoma of the mammary gland. PC-3 cells were isolated from a grade IV adenocarcinoma of the prostate. LNCaP cells were derived from a metastatic site of a carcinoma of the prostate. SKOV-3 cells were isolated from ascites of an adenocarcinoma of the ovary. OV-MZ-6 ovarian cancer cells were established from malignant ascites drained from a patient with an advanced cystadeno-carcinoma as previously published [11]. MDAMB-231 cells were cultured in high glucose Dulbecco's modified Eagle medium (DMEM; Invitrogen, Vic, Australia), supplemented with $10 \%$ fetal bovine serum (FBS) and $1 \%$ penicillin/streptomycin. PC-3, LNCaP, and SKOV-3 cells were maintained in RPMI medium (Invitrogen), supplemented with $5 \% \mathrm{FBS}, 100 \mathrm{IU} / \mathrm{ml}$ penicillin and $0.1 \mathrm{mg} / \mathrm{ml}$ streptomycin (Invitrogen). OV-MZ-6 cells were maintained in DMEM, supplemented with $10 \%$ FBS and 1 $\%$ penicillin/streptomycin.

Preparation of lycopene solutions. A water-dispersible lycopene formulation, containing beadlets made up of $10 \%$ lycopene in a matrix of carbohydrates, was provided by BASF (Ludwigshafen, Germany). The lycopene compound was dissolved in sterile phosphate-buffered saline (PBS; Invitrogen) to a final stock concentration of $1.0 \mathrm{mM}$ and frozen to maintain stability. Treatment solutions were prepared fresh from this stock concentration in the respective culture media to final concentrations of $0.1,0.5,1.0,5.0$, and $10.0 \mu \mathrm{M}$ lycopene for each experiment. For the no treatment control, a solution of PBS in the respective culture media was prepared in the concentration equivalent to the highest lycopene concentration. 
Analyses of cell viability and proliferation within monolayer cultures. The noncytotoxic AlamarBlue assay, a measure of the metabolic activity, was used to determine the cell viability upon lycopene treatment continuously over time as reported previously [12]. Cells were seeded in duplicates at a density of $3.0 \times 10^{3}$ cells/well in $100 \mu$ l culture media onto 96-well plates (Nunc, Rochester, NY, USA) and cultured in a humidified atmosphere for 4, 24, 48, 72, and 96 hrs. Lycopene solutions were added 24 hrs after cell seeding at concentrations of $0.1,0.5,1.0,5.0$, and $10.0 \mu \mathrm{M}$ in a volume of $100 \mu \mathrm{l}$ as well as the PBS control. The 4 hrs time-point was used as a seeding control without treatment. As per assay instructions, $10 \%$ AlamarBlue reagent (Biosource, Camarillo, CA, USA) was added to the culture media $4 \mathrm{hrs}$ prior to being analyzed for every time-point. Fluorescent signals (excitation $544 \mathrm{~nm}$, emission $590 \mathrm{~nm}$ ) were detected with a fluorescence plate reader (BMG PolarStar, BMG LABTECH, Offenburg, Germany). The change in cell viability was assessed for every time-point and normalized to seeding controls. This experiment was repeated three times.

The PicoGreen assay, a measure of double-stranded DNA, was used to determine the cell proliferation upon lycopene treatment over time as reported previously [12]. Cells cultured for cell viability assays were also used for PicoGreen proliferation assays (Invitrogen). As the non-cytotoxic AlamarBlue reagent allows for the subsequent performance of other assays without influencing following results [12]. AlamarBlue-containing media was discarded and 96-well plates frozen at $-80^{\circ} \mathrm{C}$ for at least $48 \mathrm{hrs}$. Proteinase $\mathrm{K}$ solution $(100 \mu \mathrm{l} ; 0.5 \mathrm{mg} / \mathrm{ml}$; Invitrogen) was added to each sample and incubated overnight at $37^{\circ} \mathrm{C} / 5 \% \mathrm{CO}_{2}$, followed by $8 \mathrm{hrs}$ incubation at $65^{\circ} \mathrm{C}$. A standard curve was prepared as per the manufacturer's protocol, containing DNA standard concentrations from 0-2,000 ng/ml. Fluorescent signals (excitation $480 \mathrm{~nm}$, emission $520 \mathrm{~nm}$ ) were captured using a fluorescence plate reader. The DNA content was calculated using the DNA standard curve for every time-point and normalized to seeding controls. This experiment was repeated three times. 
Analysis of cell migration using transwell chambers. The transwell migration assay was performed in 12-well plates with Millicell® hanging cell culture inserts (Merck Millipore, VIC, Australia) with a pore size of $8.0 \mu \mathrm{m}$. Cells were seeded at a density of $2.0 \mathrm{x}$ $10^{5}$ cells/well in serum-free media onto the cell culture insert. Lycopene was added at concentrations of $0.5,1.0,5.0$, and $10.0 \mu \mathrm{M}$ into both, the upper and the bottom, chambers, to avoid dilution of the compound. Ten percent FBS was added to the lower chamber as a chemo-attractant and cells were then cultured for $24 \mathrm{hrs}$. A PBS control was included as a control for random migration of cells from the upper to the bottom chamber. Then, cells remaining on the upper surface of the insert were removed. To quantify the number of migrated cells, the remaining cells on the bottom of the insert were fixed with $100 \%$ ice-cold methanol and stained with $0.5 \%$ crystal violet (Sigma-Aldrich, NSW, Australia). Absorbance was measured at $595 \mathrm{~nm}$ using a plate reader. Results were corrected for background staining and normalized to controls. This experiment was repeated three times.

Analysis of cell invasion on Matrigel-coated chambers. Transwell invasion assays were performed in 12-well plates with Millicell囚 hanging cell culture inserts. One day prior to cell seeding, inserts were coated with $100 \mu \mathrm{l} /$ well of growth factor-reduced Matrigel (SigmaAldrich). Cell seeding was performed as per cell migration assays as described above, and cells were cultured for 48 hrs. To quantify the number of invaded cells, cells on the bottom of the insert were fixed with $100 \%$ ice-cold methanol and stained with $0.5 \%$ crystal violet. Absorbance was detected at $595 \mathrm{~nm}$ using a plate reader. Results were corrected for background staining and normalized to controls. This experiment was repeated three times.

\section{Preparation of gelatine-methacrylamide-sodium hyaluronate-based hydrogels.} Gelatine-methacrylamide (GelMa) was synthesized from gelatine (Sigma-Aldrich) and methacrylic anhydride (Sigma-Aldrich) as described previously [13-15]. Briefly, GelMa polymer was mixed with PBS to obtain a $5 \%$ concentration with the extracellular matrix 
(ECM) component sodium hyaluronate (HA; $0.1 \%$; Lifecore Biomedical, Chaska, MN, USA) and cross-linked to GeIMa-HA-based hydrogels by UV-irradiation using $0.5 \mathrm{mg} / \mathrm{ml}$ of Irgacure 2959 photoinitiator (BASF). This 3D culture model was used to grow ovarian cancer cells within a 3D microenvironment as spheroids as reported before [13]. Therefore, $2.8 \times 10^{5}$ cells/1 ml GelMa-HA solution were cross-linked and separated into single hydrogels containing $1.12 \times 10^{4}$ cells/hydrogel. Treatment was carried out using two different regimes lycopene treatment $(0.5$ and $5.0 \mu \mathrm{M})$ starting on day 1 to day 14 and lycopene treatment $(0.5$ and $5.0 \mu \mathrm{M})$ from day 7 to day $14(0.5$ and $5.0 \mu \mathrm{M})$ - and no treatment controls. Lycopene was added to the 3D cultures fresh every $48 \mathrm{hrs}$ in combination with media changes. Each treatment regime was carried out using 5 different hydrogels.

Analyses of cell viability and proliferation in spheroid cultures. AlamarBlue cell viability assays were performed on days 1, 7, and 14 as reported [16]. Briefly, $4 \%$ AlamarBlue reagent was added to the culture media 6 hrs prior to being analyzed for every time-point and fluorescent signals captured using a fluorescence plate reader (excitation 544 $\mathrm{nm}$, emission $590 \mathrm{~nm}$ ). After reading AlamarBlue fluorescent signals, hydrogels were transferred into PBS until the AlamarBlue reagent diffused out of the hydrogels to perform PicoGreen proliferation assays. Colorless hydrogels were frozen at $-80^{\circ} \mathrm{C}$ for at least $48 \mathrm{hrs}$. Following proteinase $\mathrm{K}$ treatment $(0.5 \mathrm{mg} / \mathrm{ml})$ overnight at $65^{\circ} \mathrm{C}$, PicoGreen fluorescent signals (excitation $480 \mathrm{~nm}$, emission $520 \mathrm{~nm}$ ) were measured using a fluorescence plate reader. The DNA content was calculated using the DNA standard curve for every time-point and normalized to controls. This experiment was repeated three times.

Confocal laser scanning microscopy of spheroid cultures. After 14 days of 3D culture, hydrogels were washed with PBS and fixed with $4 \%$ paraformaldehyde as reported [16]. Samples were permeabilized with $0.2 \%$ Triton-X-100, washed with $0.1 \mathrm{M}$ glycine in PBS, then with PBS prior to rhodamine415-conjugated phalloidin $(0.3 \mathrm{U} / \mathrm{ml}$; Invitrogen) and 
4,6-diamidino-2-phenylindole (2.5 mg/ml; Invitrogen) staining for $1 \mathrm{~h}$ each. Two different hydrogels for each treatment regime were analyzed with a Nikon A1R confocal laser scanning microscope (Nikon Corp, Tokyo, Japan).

Scanning electron microscopy of spheroid cultures. After 14 days of 3D culture, hydrogels were fixed with $3 \%$ glutaraldehyde in $0.1 \mathrm{M}$ sodium cacodylate buffer $(\mathrm{pH} 7.3)$ for $1 \mathrm{~h}$ at $4^{\circ} \mathrm{C}$, then washed in water and dehydrated in a series of ethanol as reported [16]. Samples were critically point-dried (Denton Vacuum, Moorestown, NJ, USA) and mounted on aluminium stubs. After gold-coating in a SC 500 sputter coater (Bio-Rad, Hercules, CA, USA), two different hydrogels for each treatment regime were examined using a Quanta 200 scanning electron microscope (FEI, Hillsboro, Oregon, USA) operating at $10 \mathrm{kV}$.

Statistical analysis. For statistical analyses, SigmaStat $3.5^{\circledR}$ software was used. Data were presented as mean values \pm standard error of three biological replicate experiments. Differences between treatment regimes and the control were analyzed using a one-way analysis of variance (Anova), with Holm-Sidak post-hoc test. The level of significance was set at $p<0.05$. 


\section{Results}

\section{Lycopene reduces the viability of cells grown in monolayer}

\section{cultures.}

Lycopene treatment of all five cancer cell lines was performed 24 hrs after cell seeding to allow for cell recovery. Subsequently, cells were incubated with $0.1,0.5,1.0,5.0$, and 10.0 $\mu \mathrm{M}$ lycopene for up to $72 \mathrm{hrs}$. These concentrations represent the physiological limit between 0.1 and $2.0 \mu \mathrm{M}$ as well as the supra-physiological doses of 5.0 and $10.0 \mu \mathrm{M}$ to address the question whether further pro- or anti-tumorigenic effects can be detected. Most prominent effects on viability of the cancer cell types tested were observed after treatment with $0.5,1.0$, and $5.0 \mu \mathrm{M}$ lycopene (Fig. 1).

The viability of MDA-MB-231 breast cancer cells was significantly reduced after 4 hrs of treatment with $1.0 \mu \mathrm{M}$ lycopene up to $19 \%$ as compared to the no treatment control. Incubation with lycopene at concentrations of $0.1,1.0$, and $5.0 \mu \mathrm{M}$ over $24 \mathrm{hrs}$ led to significantly reduced viability up to $35 \%$. A significant decrease of about $20-25 \%$ of viable cells was detected at concentrations ranging from 0.5 to $5.0 \mu \mathrm{M}$ over 4,24 , and 72 hrs for LNCaP prostate cancer cells, reaching up to $28 \%$ after $24 \mathrm{hrs}$ exposure to $0.5 \mu \mathrm{M}$ lycopene. Distinctive effects on PC-3 prostate cancer cells were detected, showing a $26 \%$ reduced viability after $24 \mathrm{hrs}$ treatment with $1.0 \mu \mathrm{M}$ lycopene. This effect was also significant at lycopene concentrations of 0.5 and $5.0 \mu \mathrm{M}$ after 48 and 72 hrs incubation, with a cell viability of $10-20 \%$ under control levels. OV-MZ-6 ovarian cancer cells significantly responded to 0.5 and $5.0 \mu \mathrm{M}$ lycopene exposure with a decreased viability by $10-28 \%$ as compared to controls. After 48 hrs incubation, levels declined at all concentrations by more than $30 \%$. Lycopene effects on SKOV-3 ovarian cancer cells were less pronounced, reaching up to 15 $\%$ reduction in viability after $4 \mathrm{hrs}$ with $5.0 \mu \mathrm{M}$ lycopene.

Interestingly, a typical u-shaped curve was observed for all cancer cell types at all concentrations and time-points tested (Fig. S1). Viability declined between 0.1 and $5.0 \mu \mathrm{M}$ 
lycopene, followed by a sharp increase after treatment with $10.0 \mu \mathrm{M}$ lycopene. However, a dose of $10.0 \mu \mathrm{M}$ cannot be achieved in human plasma by consuming lycopene-rich food or lycopene-based supplements. As described previously by Allen et al., concentrations up to 2.0 $\mu \mathrm{M}$ are considered physiological [17]. Noteworthy, a non-linear dose-effect relationship has also been shown for other dietary compounds [18]. These findings suggest that lycopene overall reduces the viability of breast, prostate, and ovarian cancer cells at concentrations ranging from 0.5 to $5.0 \mu \mathrm{M}$, which is within the physiological attainable range.

\section{Lycopene has a minor impact on proliferation of cells grown in}

\section{monolayer cultures.}

The impact of lycopene on cell proliferation was less distinct than its effects on cell viability (Fig. S2). A significant reduction in proliferation was only seen after $24 \mathrm{hrs}$ of exposure to $5.0 \mu \mathrm{M}$ lycopene in OV-MZ-6 ovarian cancer cells (22\% under control level) as well as after $48 \mathrm{hrs}$ of treatment with $0.5 \mu \mathrm{M}$ lycopene in MDA-MB-231 breast cancer (24\% under control level) and LNCaP prostate cancer cells (13\% under control level). MDA-MB231 breast cancer cells and PC-3 prostate cancer cells showed a slightly reduced proliferative behavior.. Both ovarian cancer cell lines proliferated less by an overall of 10-20 $\%$ after 4 and 24 hrs of treatment but increased proliferation after exposure to lycopene over 48 and 72 hrs respectively. Thus, contrary to the cell viability results, lycopene has only a minor impact on the proliferative behavior of the cancer cell types tested.

\section{Lycopene has no influence on migratory behavior of cells.}

Using a transwell migration assay, the impact of lycopene at dosages between 0.5 and $10.0 \mu \mathrm{M}$ on migration of breast, prostate, and ovarian cancer cells was determined. None of the cell lines tested showed any significance for an altered migratory behavior (Fig. 2). MDAMB-231, OV-MZ-6, and SKOV-3 cells showed a trend for reduced migration after treatment 
with lycopene, whereas both prostate cancer cell lines tended to migrate more upon lycopene exposure. Overall, no evidence was found that lycopene has an impact on the migratory behavior of the cancer cell types tested.

\section{Lycopene influenced invasion of SKOV-3, but not OV-MZ-6}

\section{ovarian cancer cells.}

Unlike breast and prostate tumors, ovarian cancer progresses in a unique manner. Ovarian cancer cells disseminate within the abdominal cavity and form multicellular spheroids that invade into the ECM lining the peritoneum [19]. Hence, the invasion of two different ovarian cancer cell lines was analysed using growth factor-reduced Matrigel in the transwell system. SKOV-3 cells treated with 5.0 and $10.0 \mu \mathrm{M}$ lycopene reduced their invasion by $20 \%$, without reaching significance, and showed a slightly decreased invasive behavior at 0.5 and $1.0 \mu \mathrm{M}$ lycopene. OV-MZ-6 cells did not notably change their invasive behavior upon exposure to lycopene (Fig. 3).

\section{Effects of lycopene on viability and proliferation of ovarian}

\section{cancer cells grown in spheroid cultures.}

To allow multicellular spheroid formation, OV-MZ-6 and SKOV-3 ovarian cancer cells were grown within an in vitro 3D cancer model that mimics their natural tumor microenvironment $[13,16]$. Spheroid cultures were grown over 14 days and cell viability and growth investigated upon exposure to 0.5 and $5.0 \mu \mathrm{M}$ lycopene starting on day 1 , to test if lycopene can slow down spheroid growth and reduce spheroid formation, and starting on day 7, to test if lycopene can affect already formed spheroids, of 3D culture. Spheroid formation was visible on day 7 and more pronounced after 14 days of 3D culture as shown by confocal laser scanning microscopy (Fig. 4) and scanning electron microscopy (Fig. 5). Viability and proliferation data indicate that a concentration of $5.0 \mu \mathrm{M}$ lycopene was capable to decelerate 
the development of cancer cell spheroids until day 7 , but that 14 days of treatment reversed this effect, and cells responded with enhanced viability and proliferation (Figs. 4 and 6a-b).

OV-MZ-6 cells slightly reduced proliferation and viability upon treatment with lycopene until day 7 but increased both parameters after 14 days of 3D culture. Proliferation of SKOV-3 cells decreased significantly after 7 days, when treated with $0.5 \mu \mathrm{M}$ lycopene, accompanied with reduced cell viability. As with the OV-MZ-6 cells, the increase in proliferation and viability of SKOV-3 cells after 14 days of 3D culture was insignificant (Fig. 6a). Lycopene treatment with 0.5 and $5 \mu \mathrm{M}$ respectively from day 7 until day 14 resulted in increasing viability and proliferation, with a significant effect on viability of SKOV-3 cells (Fig. 6b).

These findings indicate a reduction of viability and proliferation of both ovarian cancer cell lines grown in 3D cultures for 7 days when exposed to lycopene, but also a subsequent rise in viable and proliferating cells after 14 days of $3 \mathrm{D}$ culture. Lycopene was added to the cells every $48 \mathrm{hrs}$ over the duration of the experiment. However, there is evidence that lycopene metabolites are generated very easily by initial cleavage through carotenoid monooxygenase II (CMO II). The antioxidant capacity of these lycopene metabolites is not entirely known yet, even though there is some evidence that for instance apo10'-lycopenoic acid reduced the proliferation of non-small cell lung cancer cells [20]. Apo10'-lycopenoic acid also inhibited cell growth of non-malignant bronchial epithelial and lung cancer cells [21]. It is therefore possible that oxidation products contributed to the lycopene effects seen in our 3D cultures.

\section{Discussion}

Previously published studies on lycopene and its anti-cancer effects are inconsistent and show great variation in their outcomes $[9,22]$. This might be due to different lycopene sources used ranging from tomato extract or pure lycopene to water dispersible lycopene formulations. Additional factors that influence these study outcomes are varying solubilisation techniques and differences in concentrations, sometimes well above the physiological limit. Lycopene levels as high as $2.0 \mu \mathrm{M}$ are detected in human plasma after consumption of 
tomato sauce, juice and soup and are therefore considered as physiologically attainable by humans $[17,23]$. Nevertheless, a wide range of published studies report results using supraphysiological lycopene concentrations sometimes up to $100.0 \mu \mathrm{M}[22,24-29]$. These differences in study design all need to be considered to reliably compare varying outcomes. In this study, concentrations within the physiological limit between 0.1 and $2.0 \mu \mathrm{M}$ as well as the supra-physiological doses of 5.0 and $10.0 \mu \mathrm{M}$ were tested to address the question whether further pro- or anti-tumorigenic effects can be detected.

Commonly used metabolic assays like MTT, Trypan Blue, WST-1 or Alamar Blue have been employed to assess the potential of lycopene to reduce proliferation of tumor cells. However, as reported by Quent et al. [12], these assays are not suitable to quantify cell numbers as they only detect the metabolic activity of treated cells, which can change within the cell cycle. In this study, cell viability and proliferation measurements were distinguished by using AlamarBlue and PicoGreen assays, the latter measuring the DNA content and therefore cell numbers. Overall, treatment with lycopene at physiologically attainable concentrations reduced the metabolic activity of all five cancer cell types tested, resulting in decreased viability rates as measured by AlamarBlue. Exposure to $0.1,1.0$, and $5.0 \mu \mathrm{M}$ lycopene over 24 hrs reduced the viability of MDA-MB-231 breast cancer cells by up to $35 \%$ compared to the no treatment control. Decreasing viability of breast cancer cells has been shown before by others using MCF-7 cells [28, 30]. Uppala and coworkers [31] compared carcinogenic MCF-7 cells with non-carcinogenic MCF-10 cells, describing an inhibitory lycopene effect on MCF-7 cell viability, while MCF-10 cells were unaffected, implicating that an oncogene as a target is present to observe the lycopene effect [31].

OV-MZ-6 ovarian cancer cells had a reduced viability by more than $30 \%$ after 48 hrs exposure to lycopene at physiological concentrations. SKOV-3 ovarian cancer cells responded with a $15 \%$ decrease in viability only after $4 \mathrm{hrs}$. So far, to our knowledge, this effect on ovarian cancer cell viability has not been shown in the literature before. The only in 
vitro study examining the effect of lycopene on ovarian cancer cells reported a slightly reduced viability of $C R L-11731$ cells at a dose of $1.0 \mu \mathrm{M}$, with increasing rates up to $50.0 \mu \mathrm{M}$, but the latter by far exceeds the physiological limit [24].

The most intensively investigated cancer type in the field is prostate cancer. This study confirms published data by others regarding viability of $\mathrm{LNCaP}$ and PC-3 prostate cancer cells after lycopene treatment. A dose of $0.5 \mu \mathrm{M}$ lycopene over $24 \mathrm{hrs}$ decreased viability in LNCaP cells by up to $28 \%$, whereas PC-3 cells responded to $1.0 \mu \mathrm{M}$ lycopene with a $26 \%$ reduction compared to no treatment controls. Kotake-Nara et al. [32] reported an even greater reduction in cell viability of $58 \%$ with $20.0 \mu \mathrm{M}$ lycopene. This has also been observed by Yang and coworkers [33] using lycopene concentrations within the physiological range. Hwang et al. [34] incubated LNCaP cells with tomato paste extract resulting in a decrease in viability of more than $50 \%$. The authors mentioned that also other ingredients than lycopene could be considered for this outcome, as the extract consists of a mixture of nutrients [34].

The lycopene viability data reflect u-shaped curves for all cancer cell types and time-points. Viability decreases at concentrations between 0.1 and $5.0 \mu \mathrm{M}$, followed by a subsequent sharp rise upon $10.0 \mu \mathrm{M}$ lycopene. The dose-response relationship between a compound and its measured physiological effect is of considerable importance. There is evidence that this dose-response relationship is not always linear for dietary compounds and that a protective effect, measured at lower doses, can become harmful at higher amounts. This study outlines these effects at concentrations that have not been measured in humans after consuming a lycopene-rich diet so far. Nevertheless, it is reasonable to keep in mind that over-excessive consumption of supplements is not always beneficial and can even switch from a healthy benefit to a harmful effect.

While our viability data, showing a clear decrease in viability for all five cancer cell types after lycopene treatment, indicate very strongly that lycopene plays a supportive role against breast, prostate, and ovarian cancer cells, the proliferation results do not completely support this assumption. Significantly reduced proliferation rates were only observed for MDA-MB- 
231 breast cancer and LNCaP prostate cancer cells after 48 hrs treatment with $0.5 \mu \mathrm{M}$ lycopene as well as for OV-MZ-6 ovarian cancer cells after $24 \mathrm{hrs}$ exposure to $5.0 \mu \mathrm{M}$ lycopene. Indeed, these overall results reflect a reduction in cell proliferation upon lycopene treatment for the cancer cell types tested, but except for the above outlined cases, there was no significance. Other studies report reduced proliferation of DU145 prostate cancer cells [22] as well as MCF-7 and MDA-MB-231 breast cancer cells [35] after treatment with lycopene at concentrations between 10.0 and $25.0 \mu \mathrm{M}$, which is again above the physiological limit [22, 35]. Since effects on cell viability and proliferation were observed, apoptosis assays are currently being performed to further elucidate lycopene's impact on cancer cell functions.

Besides influencing tumor cell viability and proliferation, lycopene has also been suggested to exert anti-metastatic effects in highly aggressive cancers. Aggressive cancer cells have the capability to migrate from the primary site, invade into the surrounding tissues and promote angiogenesis [36]. Degrading basement membrane and ECM proteins is one key metastatic step, which is mediated by matrix metalloproteinases (MMP) [37]. Huang and coworkers [38] reported a lycopene-induced inhibition of migration and invasion of SK-Hep-1 hepatocellular carcinoma cells at a dose of $5.0 \mu \mathrm{M}$, accompanied by up-regulation of the metastasis suppressor gene nm23-H1. Moreover, in another study conducted by this group this led to reduced MMP-9 expression and activity in SK-Hep-1 cells upon lycopene exposure [36]. Lin et al. [39] showed a reduced invasive behavior of HT-29 colon cancer cells, with suppressed expression of MMP-7 at lycopene concentrations between 0.1 and $2.0 \mu \mathrm{M}$ [39]. In addition, Bureyko and co-workers [40] found a decrease in $\alpha_{2} \beta_{1}$ integrin expression in 22Rv1, LNCaP and PC-3 prostate cancer cells upon treatment with $10.0 \mu \mathrm{M}$ lycopene [40]. In contrast, in this study, migration of $\mathrm{LNCaP}$ and PC-3 cells was not reduced. A slightly decreased migration was observed in MDA-MB-231 breast cancer cells without reaching significance. Migration and invasion of OV-MZ-6 ovarian cancer cells was not affected by lycopene treatment. SKOV-3 ovarian cancer cells migrated and invaded slightly less upon lycopene treatment 
without being significant. These results do therefore not confirm the capability of lycopene to inhibit migration and invasion in the different cancer cell types tested.

Over the past decade, 3D cell culture approaches have become increasingly important for in vitro and in vivo studies, particularly in the field of cell biology. These 3D models have been developed to overcome the limitations of traditional monolayer cultures, thereby mimicking the 3D tissue architecture and natural microenvironment [41]. They provide a powerful toolbox to study cancer cell biology and the tumor's interaction with its niche, and thus, a test system to investigate anti-cancer targets. The tumor's microenvironment and the properties of the surrounding ECM have a clear impact on specific behaviors of cancer cells, such as proliferation, invasion and the potential to undergo apoptosis [42]. Therefore, 3D cancer models gradually replace monolayer drug screening strategies in order to achieve a faithful mimic of the 3D structure and signaling milieu in which the cancer cells reside within patients [16]. In this study, a GelMa-based hydrogel was used, in which HA was incorporated as a representative ECM component, to allow spheroid formation of ovarian cancer cells. This $3 \mathrm{D}$ model was not used as a direct comparison to monolayer cultures, but rather as a platform that is suitable to allow spheroid growth in a physiological context, thereby bridging the gap between in vitro and in vivo studies [13]. As a proof of concept, the impact of lycopene on viability and proliferation of two different ovarian cancer cell lines was examined. This 3D model induced spheroid formation and growth in OV-MZ-6 and SKOV-3 cells after 7 days of 3D culture, which was more prominent at day 14 . One week of lycopene treatment of SKOV3 cells grown within GelMa-HA-based hydrogels decreased proliferation and viability. This effect was already observed at a concentration of $0.5 \mu \mathrm{M}$, which reflects physiological levels. Lycopene-treated OV-MZ-6 cells showed a reduced proliferation and viability only at a dose of $5.0 \mu \mathrm{M}$. Interestingly, both ovarian cancer cell lines responded with increasing viability and proliferation after 14 days of 3D culture upon lycopene treatment. Lycopene was added to the cells every 48 hrs over the duration of the experiment. Hence, there is no reason to assume 
that internalized levels declined over time. Both treatment regimes did not result in different outcomes. In this study, a lycopene beadlet formulation was used, which contains $10 \%$ lycopene and $90 \%$ carbohydrates. This high carbohydrate amount could provide an ideal nutrient for cancer cells as it might diffuse faster into the hydrogel than lycopene itself. Therefore, the increased proliferation over a prolonged treatment period might be attributed to the carbohydrate content in the culture media. The used control solution contained PBS only and no placebo beadlets. Preliminary results of 3D studies with placebo beadlets using PEG-based hydrogels indicate that there was no change in proliferation of OV-MZ-6 cells treated with control (placebo) or lycopene-containing beadlets (Fig. S3). However, there was a slight reduction of proliferation with both lycopene concentrations used ( 2 and $5 \mu \mathrm{M})$ over the entire treatment period of 14 days, indicating that the carbohydrates could indeed be a reason for the enhanced proliferation seen, but these results did not reach significance.

On the other hand, the increase in proliferation after prolonged exposure times might be one of the reasons how lycopene exerts synergistic effects in combination with cytotoxic drugs $[24,43,44]$. Due to the antioxidative properties of lycopene, concerns were raised, whether both cancer and normal cells can be protected by this carotenoid when exposed to docetaxel [45]. Contrary to this assumption, Tang et al. [44] demonstrated that the combination of docetaxel with lycopene significantly enhanced the cancer cells' response to the cytotoxic drug. Taxanes bind to $\beta$-tubulin, thereby leading to abnormalities in the function of microtubules and defective spindle formation during metaphase, causing cell cycle arrest and subsequent apoptosis [46]. Lycopene induced an increase in cell proliferation, and therefore, could result in enhanced accessibility of cancer cells towards chemotherapy. This assumption needs to be confirmed in future studies, for example by using 3D cell culture approaches.

In conclusion, Lycopene's preventive effects on cancer cell functions are still very heterogeneous. These inconsistent results arise mainly from different lycopene sources and solubilisers as well as the wide range of concentrations, which, in many studies, exceed physiologically attainable levels. For biochemical studies, usually lycopene itself as a 
compound is tested, rather than its active metabolite, which can cause the beneficial effect in humans.

The findings from this study on cell viability, measured in monolayer cultures, reflect the potential chemo-preventive effects of lycopene on breast, prostate, and ovarian cancer cells at physiological concentrations that have been found in humans after consuming a lycopenerich diet. However, proliferation rates, which give a more accurate idea on the actual growth of the cancer cells, did not decline significantly. Furthermore, this study did not explicitly show that lycopene prevents cancer cell migration and invasion. Using a 3D cell culture approach, that reflects the natural tumor microenvironment, both viability and growth of two different ovarian cancer cell lines were reduced after exposure to lycopene at physiological concentrations for 7 days. However, prolonged treatment with lycopene resulted in increasing cell proliferation. Whether this effect is caused by carbohydrates, a major component of the lycopene formulation used in this study, rather than by lycopene itself, is currently part of ongoing experiments.

To date, the beneficial effects of lycopene in the human diet are evident. Supplementing the food intake with lycopene as a combination treatment for breast, prostate or ovarian cancer cannot be supported from this data. More harmonized and well-conducted in vitro and in vivo studies are necessary to investigate the supportive effect of supplemental lycopene in cancer treatment. 


\section{Acknowledgements}

N.P.H. and B.M.H. conducted the research. C.T. performed the scanning electron microscopy. E.K. performed the confocal laser scanning microscopy. T.R., J.F. and S.C. provided the lycopene compound. J.A.C., D.W.H. and D.L. designed the research. N.P.H., T.R. and D.L. wrote the manuscript. All authors read and approved the final manuscript. Funding for this study was provided by the Australian Research Council, the Cancer Council Queensland, the National Health and Medical Research Council of Australia and BASF (Ludwigshafen, Germany). 


\section{References}

1. Genkinger JM, Platz EA, Hoffman SC, Comstock GW, Helzlsouer KJ. Fruit, vegetable, and antioxidant intake and all-cause, cancer, and cardiovascular disease mortality in a community-dwelling population in Washington County, Maryland. American journal of epidemiology. 2004;160(12):122333. Epub 2004/12/08. doi: 10.1093/aje/. PubMed PMID: 15583375.

2. Rieck G, Fiander A. The effect of lifestyle factors on gynaecological cancer. Best practice \& research Clinical obstetrics \& gynaecology. 2006;20(2):227-51. Epub 2006/03/18. doi: 10.1016/j.bpobgyn.2005.10.010. PubMed PMID: 16543119.

3. Trottier G, Bostrom PJ, Lawrentschuk N, Fleshner NE. Nutraceuticals and prostate cancer prevention: a current review. Nature reviews Urology. 2010;7(1):21-30. Epub 2009/12/10. doi: 10.1038/nrurol.2009.234. PubMed PMID: 19997071.

4. Pan SY, Ugnat AM, Mao Y, Wen SW, Johnson KC. A case-control study of diet and the risk of ovarian cancer. Cancer epidemiology, biomarkers \& prevention : a publication of the American Association for Cancer Research, cosponsored by the American Society of Preventive Oncology. 2004;13(9):1521-7. Epub 2004/09/03. PubMed PMID: 15342455.

5. Pan SY, Zhou J, Gibbons L, Morrison H, Wen SW. Antioxidants and breast cancer risk- a population-based case-control study in Canada. BMC cancer. 2011;11:372. Epub 2011/08/26. doi: 10.1186/1471-2407-11-372. PubMed PMID: 21864361; PubMed Central PMCID: PMC3224257.

6. Khan N, Afaq F, Mukhtar H. Cancer chemoprevention through dietary antioxidants: progress and promise. Antioxidants \& redox signaling. 2008;10(3):475-510. Epub 2007/12/25. doi: 10.1089/ars.2007.1740. PubMed PMID: 18154485.

7. Kalra EK. Nutraceutical--definition and introduction. AAPS pharmSci. 2003;5(3):E25. Epub 2003/11/19. doi: 10.1208/ps050325. PubMed PMID: 14621960; PubMed Central PMCID: PMC2750935.

8. Brower V. Nutraceuticals: poised for a healthy slice of the healthcare market? Nature biotechnology. 1998;16(8):728-31. Epub 1998/08/14. doi: 10.1038/nbt0898-728. PubMed PMID: 9702769.

9. Holzapfel NP, Holzapfel BM, Champ S, Feldthusen J, Clements J, Hutmacher DW. The potential role of lycopene for the prevention and therapy of prostate cancer: from molecular mechanisms to clinical evidence. International journal of molecular sciences. 2013;14(7):14620-46. Epub 2013/07/17. doi: 10.3390/ijms140714620. PubMed PMID: 23857058.

10. AICR. http://www.aicr.org/foods-that-fight-cancer/foodsthatfightcancer tomatoes.html 2015 [cited 2015 27.01.2015]. Available from: http://www.aicr.org/foods-that-fightcancer/foodsthatfightcancer tomatoes.html.

11. Mobus V, Gerharz CD, Press U, Moll R, Beck T, Mellin W, et al. Morphological, immunohistochemical, and biochemical characterization of 6 newly established human ovariancarcinoma cell-lines. International Journal of Cancer. 1992;52(1):76-84. doi: 10.1002/ijc.2910520115. PubMed PMID: WOS:A1992JJ72300014.

12. Quent VM, Loessner D, Friis T, Reichert JC, Hutmacher DW. Discrepancies between metabolic activity and DNA content as tool to assess cell proliferation in cancer research. Journal of cellular and molecular medicine. 2010;14(4):1003-13. Epub 2010/01/20. doi: 10.1111/j.15824934.2010.01013.x. PubMed PMID: 20082656.

13. Kaemmerer E, Melchels FP, Holzapfel BM, Meckel T, Hutmacher DW, Loessner D. Gelatine methacrylamide-based hydrogels: an alternative three-dimensional cancer cell culture system. Acta Biomater. 2014;10(6):2551-62. Epub 2014/03/05. doi: 10.1016/j.actbio.2014.02.035. PubMed PMID: 24590158.

14. Schuurman W, Levett PA, Pot MW, van Weeren PR, Dhert WJ, Hutmacher DW, et al. Gelatinmethacrylamide hydrogels as potential biomaterials for fabrication of tissue-engineered cartilage constructs. Macromolecular bioscience. 2013;13(5):551-61. Epub 2013/02/20. doi: 10.1002/mabi.201200471. PubMed PMID: 23420700. 
15. Van Den Bulcke AI, Bogdanov B, De Rooze N, Schacht EH, Cornelissen M, Berghmans H. Structural and rheological properties of methacrylamide modified gelatin hydrogels. Biomacromolecules. 2000;1(1):31-8. Epub 2001/11/17. PubMed PMID: 11709840.

16. Loessner D, Stok KS, Lutolf MP, Hutmacher DW, Clements JA, Rizzi SC. Bioengineered 3D platform to explore cell-ECM interactions and drug resistance of epithelial ovarian cancer cells. Biomaterials. 2010;31(32):8494-506. Epub 2010/08/17. doi: 10.1016/j.biomaterials.2010.07.064. PubMed PMID: 20709389.

17. Allen CM, Schwartz SJ, Craft NE, Giovannucci EL, De Groff VL, Clinton SK. Changes in plasma and oral mucosal lycopene isomer concentrations in healthy adults consuming standard servings of processed tomato products. Nutrition and cancer. 2003;47(1):48-56. Epub 2004/02/11. doi: 10.1207/s15327914nc4701_6. PubMed PMID: 14769537.

18. Mayne ST, Handelman GJ, Beecher G. Beta-Carotene and lung cancer promotion in heavy smokers--a plausible relationship? Journal of the National Cancer Institute. 1996;88(21):1513-5. Epub 1996/11/06. PubMed PMID: 8901847.

19. Lengyel E. Ovarian cancer development and metastasis. Am J Pathol. 2010;177(3):1053-64. Epub 2010/07/24. doi: 10.2353/ajpath.2010.100105. PubMed PMID: 20651229; PubMed Central PMCID: PMC2928939.

20. Lindshield BL, Canene-Adams K, Erdman JW, Jr. Lycopenoids: are lycopene metabolites bioactive? Archives of biochemistry and biophysics. 2007;458(2):136-40. doi: 10.1016/j.abb.2006.09.012. PubMed PMID: 17067545.

21. Mein JR, Lian F, Wang XD. Biological activity of lycopene metabolites: implications for cancer prevention. Nutrition reviews. 2008;66(12):667-83. doi: 10.1111/j.1753-4887.2008.00120.x. PubMed PMID: 19019036.

22. Ford NA, Elsen AC, Zuniga K, Lindshield BL, Erdman JW, Jr. Lycopene and apo-12'lycopenal reduce cell proliferation and alter cell cycle progression in human prostate cancer cells. Nutrition and cancer. 2011;63(2):256-63. Epub 2011/01/06. doi: 10.1080/01635581.2011.523494. PubMed PMID: 21207319.

23. Hantz HL, Young LF, Martin KR. Physiologically attainable concentrations of lycopene induce mitochondrial apoptosis in LNCaP human prostate cancer cells. Experimental biology and medicine. 2005;230(3):171-9. Epub 2005/03/01. PubMed PMID: 15734720.

24. Czeczuga-Semeniuk E, Bielawski T, Lemancewicz D, Rusak M, Wolczynski S. Vitamin A family compounds, estradiol, and docetaxel in proliferation, apoptosis and immunocytochemical profile of human ovary endometrioid cancer cell line CRL-11731. Folia histochemica et cytobiologica / Polish Academy of Sciences, Polish Histochemical and Cytochemical Society. 2009;47(5):S127-35. Epub 2010/01/14. doi: 10.2478/v10042-009-0052-9. PubMed PMID: 20067883.

25. Kanagaraj P, Vijayababu MR, Ravisankar B, Anbalagan J, Aruldhas MM, Arunakaran J. Effect of lycopene on insulin-like growth factor-I, IGF binding protein-3 and IGF type-I receptor in prostate cancer cells. Journal of cancer research and clinical oncology. 2007;133(6):351-9. Epub 2007/01/16. doi: 10.1007/s00432-006-0177-6. PubMed PMID: 17219202.

26. Park YO, Hwang ES, Moon TW. The effect of lycopene on cell growth and oxidative DNA damage of Hep3B human hepatoma cells. BioFactors. 2005;23(3):129-39. Epub 2006/01/18. PubMed PMID: 16410635.

27. Zhang X, Wang Q, Neil B, Chen X. Effect of lycopene on androgen receptor and prostatespecific antigen velocity. Chinese medical journal. 2010;123(16):2231-6. Epub 2010/09/08. PubMed PMID: 20819671.

28. Fornelli F, Leone A, Verdesca I, Minervini F, Zacheo G. The influence of lycopene on the proliferation of human breast cell line (MCF-7). Toxicology in vitro : an international journal published in association with BIBRA. 2007;21(2):217-23. Epub 2006/12/05. doi: 10.1016/j.tiv.2006.09.024. PubMed PMID: 17140762.

29. Rafi MM, Kanakasabai S, Reyes MD, Bright JJ. Lycopene modulates growth and survival associated genes in prostate cancer. J Nutr Biochem. 2013;24(10):1724-34. Epub 2013/06/12. doi: 10.1016/j.jnutbio.2013.03.001. PubMed PMID: 23746934. 
30. Teodoro AJ, Oliveira FL, Martins NB, Maia Gde A, Martucci RB, Borojevic R. Effect of lycopene on cell viability and cell cycle progression in human cancer cell lines. Cancer cell international. 2012;12(1):36. Epub 2012/08/08. doi: 10.1186/1475-2867-12-36. PubMed PMID: 22866768; PubMed Central PMCID: PMC3492052.

31. Uppala PT, Dissmore T, Lau BH, Andacht T, Rajaram S. Selective inhibition of cell proliferation by lycopene in MCF-7 breast cancer cells in vitro: a proteomic analysis. Phytotherapy research : PTR. 2013;27(4):595-601. Epub 2012/06/22. doi: 10.1002/ptr.4764. PubMed PMID: 22718574.

32. Kotake-Nara E, Kushiro M, Zhang H, Sugawara T, Miyashita K, Nagao A. Carotenoids affect proliferation of human prostate cancer cells. The Journal of nutrition. 2001;131(12):3303-6. Epub 2001/12/12. PubMed PMID: 11739884.

33. Yang CM, Lu IH, Chen HY, Hu ML. Lycopene inhibits the proliferation of androgendependent human prostate tumor cells through activation of PPARgamma-LXRalpha-ABCA1 pathway. J Nutr Biochem. 2012;23(1):8-17. Epub 2011/02/22. doi: 10.1016/j.jnutbio.2010.10.006. PubMed PMID: 21334870.

34. Hwang ES, Bowen PE. Effects of lycopene and tomato paste extracts on DNA and lipid oxidation in LNCaP human prostate cancer cells. BioFactors. 2005;23(2):97-105. Epub 2005/09/24. PubMed PMID: 16179751.

35. Prakash P, Russell RM, Krinsky NI. In vitro inhibition of proliferation of estrogen-dependent and estrogen-independent human breast cancer cells treated with carotenoids or retinoids. The Journal of nutrition. 2001;131(5):1574-80. Epub 2001/05/08. PubMed PMID: 11340118.

36. Huang CS, Fan YE, Lin CY, Hu ML. Lycopene inhibits matrix metalloproteinase-9 expression and down-regulates the binding activity of nuclear factor-kappa B and stimulatory protein-1. J Nutr Biochem. 2007;18(7):449-56. Epub 2006/10/20. doi: 10.1016/j.jnutbio.2006.08.007. PubMed PMID: 17049831.

37. Palozza P, Simone RE, Catalano A, Mele MC. Tomato lycopene and lung cancer prevention: from experimental to human studies. Cancers. 2011;3(2):2333-57. Epub 2011/01/01. doi: 10.3390/cancers3022333. PubMed PMID: 24212813; PubMed Central PMCID: PMC3757421.

38. Huang CS, Shih MK, Chuang CH, Hu ML. Lycopene inhibits cell migration and invasion and upregulates Nm23-H1 in a highly invasive hepatocarcinoma, SK-Hep-1 cells. The Journal of nutrition. 2005;135(9):2119-23. Epub 2005/09/06. PubMed PMID: 16140886.

39. Lin MC, Wang FY, Kuo YH, Tang FY. Cancer chemopreventive effects of lycopene: suppression of MMP-7 expression and cell invasion in human colon cancer cells. Journal of agricultural and food chemistry. 2011;59(20):11304-18. Epub 2011/09/20. doi: 10.1021/jf202433f. PubMed PMID: 21923160.

40. Bureyko T, Hurdle H, Metcalfe JB, Clandinin MT, Mazurak VC. Reduced growth and integrin expression of prostate cells cultured with lycopene, vitamin $\mathrm{E}$ and fish oil in vitro. The British journal of nutrition. 2009;101(7):990-7. Epub 2008/08/23. doi: 10.1017/S0007114508051684. PubMed PMID: 18718045 .

41. Burdett E, Kasper FK, Mikos AG, Ludwig JA. Engineering tumors: a tissue engineering perspective in cancer biology. Tissue engineering Part B, Reviews. 2010;16(3):351-9. Epub 2010/01/23. doi: 10.1089/ten.TEB.2009.0676. PubMed PMID: 20092396.

42. Sterling JA, Edwards JR, Martin TJ, Mundy GR. Advances in the biology of bone metastasis: how the skeleton affects tumor behavior. Bone. 2011;48(1):6-15. Epub 2010/07/21. doi: 10.1016/j.bone.2010.07.015. PubMed PMID: 20643235.

43. Czeczuga-Semeniuk E, Lemancewicz D, Wolczynski S. Can vitamin A modify the activity of docetaxel in MCF-7 breast cancer cells? Folia histochemica et cytobiologica / Polish Academy of Sciences, Polish Histochemical and Cytochemical Society. 2007;45 Suppl 1:S169-74. Epub 2008/04/15. PubMed PMID: 18292828.

44. Tang Y, Parmakhtiar B, Simoneau AR, Xie J, Fruehauf J, Lilly M, et al. Lycopene enhances docetaxel's effect in castration-resistant prostate cancer associated with insulin-like growth factor I receptor levels. Neoplasia. 2011;13(2):108-19. Epub 2011/03/16. PubMed PMID: 21403837; PubMed Central PMCID: PMC3033590. 
45. Lawenda BD, Kelly KM, Ladas EJ, Sagar SM, Vickers A, Blumberg JB. Should supplemental antioxidant administration be avoided during chemotherapy and radiation therapy? Journal of the National Cancer Institute. 2008;100(11):773-83. Epub 2008/05/29. doi: 10.1093/jnci/djn148. PubMed PMID: 18505970.

46. Noguchi S. Predictive factors for response to docetaxel in human breast cancers. Cancer science. 2006;97(9):813-20. Epub 2006/06/30. doi: 10.1111/j.1349-7006.2006.00265.x. PubMed PMID: 16805818. 


\section{Figure legends}

Fig. 1: Viability of MDA-MB-231, LNCaP, PC-3, OV-MZ-6, and SKOV-3 cells after treatment with lycopene. Viability of MDA-MB-231 cells was significantly decreased after exposure to $0.1,1.0$ and $5.0 \mu \mathrm{M}$ lycopene after $24 \mathrm{hrs}$. LNCaP cells responded with significantly reduced viability rates after 4,24 , and 72 hrs of treatment. PC-3 cells also showed an explicit drop in viability, especially at 1.0 and/or $5.0 \mu \mathrm{M}$ concentrations at all timepoints. A distinct reduction in viability was seen in OV-MZ-6 cells after 24 and 48 hrs exposure to 0.5 and $5.0 \mu \mathrm{M}$ lycopene. Interestingly, SKOV-3 cells were relatively unaffected by treatment with lycopene. Dashed lines represent no treatment controls. Asterisks indicate $\mathrm{p}<0.05$.

Fig. 2: Influence of lycopene on migration rates of MDA-MB-231, LNCaP, PC-3, OV-MZ6, and SKOV-3 cells. MDA-MB-231 cells responded at 0.5 and $0.1 \mu \mathrm{M}$ with a reduced migrative behavior; however, this was not significant. Migration rates of LNCaP and PC-3 cells increased upon exposure to all lycopene concentrations without reaching significance. OV-MZ-6 cells responded with slightly reduced migration at lower concentrations, which increased at higher levels. SKOV-3 cells were relatively unaffected at all doses. Dashed lines represent no treatment controls.

Fig. 3: Impact of Iycopene treatment on invasion of OV-MZ-6 and SKOV-3 cells. Both ovarian cancer cell lines did not respond to lycopene with significant changes in their invasive behavior; however, SKOV-3 cells showed a trend towards a reduced migration after treatment with 5.0 and 10.0 $\mu \mathrm{M}$ lycopene. Dashed lines represent no treatment controls.

Fig. 4: Confocal laser scanning micrographs of OV-MZ-6 cells grown in GelMa-HAbased hydrogels. A - G shows treatment with lycopene from day 1 to day $14 ; \mathrm{H}-\mathrm{K}$ shows 
treatment with lycopene from day 7 to day 14. A) No treatment control, day 1: evenly distributed cells within the hydrogel; B) No treatment control, day 7: first spheroids begin to form; C) 7 days treatment with $0.5 \mu \mathrm{M}$ lycopene: small spheroids visible; D) 7 days treatment with $5.0 \mu \mathrm{M}$ lycopene: no visual difference to C; E) No treatment control, day 14: spheroids clearly visible; F) 14 days treatment with $0.5 \mu \mathrm{M}$ lycopene: spheroids clearly visible; G) 14 days treatment with $5.0 \mu \mathrm{M}$ lycopene: no visual difference to $\mathrm{F} ; \mathbf{H}$ ) Control group, day 14 : spheroids clearly visible (as per E); I) 7 days treatment with $0.5 \mu \mathrm{M}$ lycopene starting on day 7; K) 7 days treatment with $5.0 \mu \mathrm{M}$ lycopene starting on day 7 . The confocal images show that there is no difference in spheroid size and number between both lycopene treatment regimes. Scale bars, $100 \mu \mathrm{m}$.

Fig. 5: Scanning electron micrographs of OV-MZ-6 cells grown within GelMa-HA-based hydrogels. Cells are shown before (left side) and after (right side) lycopene treatment. Scale bars, $20 \mu \mathrm{m}$.

Fig. 6a: Effect of lycopene treatment from day 1 until day 14 on proliferation and viability of OV-MZ-6 and SKOV-3 cells grown within GelMa-HA-based hydrogels. Proliferation and viability of OV-MZ-6 cells on day 7 was relatively unaffected, with a slight increase in viable cells and cell numbers after 14 days of treatment. Proliferation and viability of SKOV-3 cells significantly decreased after 7 days of treatment with $0.5 \mu \mathrm{M}$ lycopene, but increased after 14 days as well. Asterisk indicates $p<0.05$.

Fig. 6b: Effect of lycopene treatment from day 7 until day 14 on proliferation and viability of OV-MZ-6 and SKOV-3 cells grown within GeIMa-HA-based hydrogels. Both, proliferation and viability of OV-MZ-6 and SKOV-3 cells was increased after treatment with lycopene, reaching significance only for viability of SKOV-3 cells. Asterisks indicate $p<0.05$. 


\section{Supporting Information}

Fig. S1: Viability of MDA-MB-231, LNCaP, PC-3, OV-MZ-6, and SKOV-3 cells after treatment with lycopene. U-shaped response curves were observed for every cell line and time point, showing a drop in cell viability at lycopene doses between 0.1 and $5.0 \mu \mathrm{M}$, followed by a sharp rise at $10.0 \mu \mathrm{M}$. Straight black lines represent no treatment controls.

Fig. S2: Impact of lycopene treatment on proliferation of MDA-MB-231, LNCaP, PC-3, OV-MZ-6, and SKOV-3 cells. Cancer cell lines responded overall with decreasing growth rates at 4,24 , and 48 hrs of treatment. This was only significant for OV-MZ-6 cells after 24 hrs treatment with $5.0 \mu \mathrm{M}$ lycopene, as well as for MDA-MB-231 cells and LNCaP cells after $48 \mathrm{hrs}$ incubation with $0.5 \mu \mathrm{M}$ lycopene. Exposure for $72 \mathrm{hrs}$ led to rising proliferation rates of LNCaP, PC-3, and SKOV-3 cells. Dashed lines represent no treatment controls. Asterisk indicates $p<0.05$.

Fig. S3: Effect of lycopene-containing and placebo beadlets on proliferation of OV-MZ6 cells. Proliferation of OV-MZ-6 cells was marginally reduced after treatment with lycopene in both treatment regimes (treatment from day 1 until day 14 as well as treatment from day 7 until day 14). Placebo beadlets (upper line, filled circles) did not reduce cell proliferation in comparison to lycopene-containing beadlets. 